\title{
Great Vessel Excursion: Prone Versus Supine Position
}

\author{
ALEXANDER R. RICCIO, MD, ANDREW BISHOP, ALLEN L. CARL, MD \\ Department of Neurosurgery, Albany Medical Center, Albany, New York
}

\begin{abstract}
Background: It is theorized that pedicle screws could be placed into the anterior vertebral cortex to increase biomechanical strength by $20 \%$ to $25 \%$. Although stereotactic navigational tools allow for accurate docking of spinal implants, no data exist regarding operative positioning as it relates to great vessel alignment. Our hypothesis is that the great vessels fall anteriorly, with prone positioning providing a safer margin for implantation of screws from a posterior approach.

Methods: Volunteers underwent magnetic resonance imaging of the spine. Twenty healthy volunteers, affiliated with the academic medical center performing the study, underwent magnetic resonance imaging in both the supine and prone positions. Measurements were taken of the distance $(\mathrm{mm})$ from the projected tip of a pedicle screw to the neighboring great vessels.

Measurements were made at every other vertebral level from T3 to L5 by bisecting the pedicle in the transverse and sagittal planes and projecting the trajectory of a screw to the anterior cortex. We then evaluated great vessel position in relationship to the tip of the projected pedicle screw at the anterior cortex in the supine and prone orientations.

Results: The vessels were found to lie in a range of 2 to $10 \mathrm{~mm}$ from the anterior cortex. The comparison between the supine and prone positions showed that the great vessels in the lumbar region are held securely by the surrounding soft tissue. However, in the thoracic spine, anterior excursion does occur, just not as we expected. The aorta moves anteriorly while prone by 1.4 to $5 \mathrm{~mm}$; however, its movement causes it to slide forward along the vertebra, shortening the distance to the anterior cortex. As a result, the screw trajectory is in a riskier geographic location. In the thoracolumbar area, the inferior vena cava translates 1.7 to $2.9 \mathrm{~mm}$.

Conclusions: These data suggest that the risks of vascular injury from anterior cortical fixation of the vertebra using pedicle screws placed posteriorly in the prone position are apparent. In the lumbar region, the upper thoracic region around the aortic arch, and the thoracolumbar junction the great vessels remain close to the vertebra. While in the mid-thoracic region, the aorta moves closer to the area of screw penetration anteriorly when the subject is prone.

Clinical Relevance: Spine surgeons commonly attempt pedicle screw placement into the anterior cortex of the vertebral body. Our study helps elucidate the inherent risks of this technique due to vessel positioning when prone.
\end{abstract}

Other \& Special Categories

Keywords: pedicle screw, bicortical, great vessel, spine

\section{INTRODUCTION}

Accurate placement of pedicle screws for spinal fixation is imperative. Misplacement of screws ranges from $5 \%$ to $41 \%$, , resulting in potentially fatal complications. ${ }^{3-5}$ Recent advances in stereotactic guided methods have increased the accuracy and safety margin of screw placement. ${ }^{6,7}$ This technology could potentially allow for anterior cortical purchase of the vertebral body, dramatically increasing screw strength by $20 \%$ to $31 \%{ }^{8,9}$

Because of the positioning and proximity of the great vessels to the spine, potential vascular injury increases the risk associated with the anterior cortical purchase of pedicle screws. If in a prone position, the vessels were to actually move anteriorly away from the spine because of gravitational forces, a margin of safety might allow for this type of anterior fixation. Case-by-case determination of specific measurements may be necessary due to individual anatomy. ${ }^{10}$

We hypothesized that the great vessels fall anteriorly with prone positioning, providing a safer margin for implantation of screws. To determine the margin of safety, magnetic resonance images of the spine were compared in healthy individuals in the prone and supine position.

\section{MATERIALS AND METHODS}

Twenty healthy volunteers with no history of spinal disease were evaluated. A General Electric 1.5 tesla magnetic imaging scanner was used for all tests. Spines were imaged from T3 to L5 in the 
Table 1. The distance between the projected tip of the screw and the aorta.

\begin{tabular}{lcccrrrr}
\hline Vertebra & L5 & L3 & L1 & T11 & T9 & T7 & T5 \\
\hline Prone, $\mathrm{mm}$ & 2.8 & 3.4 & 2.5 & 2.6 & 3.6 & 3.9 & 9.1 \\
Supine, mm & 3.3 & 3.1 & 2.0 & 4.0 & 8.2 & 9.0 & -0 \\
Change, $\mathrm{mm}$ & -0.5 & 0.3 & 0.5 & -1.4 & -4.6 & -5.1 & -2.9 \\
\hline
\end{tabular}

supine and prone positions. Oblique images were obtained at every other spinal level through the pedicles.

Measurements were then made using the General Electric Advantage Windows Software (Milwaukee, Wisconsin) on a Sun Microsystems computer. Ideal pedicle screw placement was then determined, bisecting the pedicles in both the transverse and sagittal planes. The trajectory of the screw was then projected to the anterior cortex; the shortest distance from the intersection of the screw with the cortex to the corresponding great vessel was then determined: aorta on the left, inferior vena cava on the right, iliac arteries and veins at L5.

\section{RESULTS}

Age range of the participants was 26 to 36 years, with a mean age of 27.8 , comprising 16 male and 4 female volunteers. Spinal levels T3 to L5 were imaged. For the inferior vena cava, its measurements could be performed from T9 to L5 as it enters the right atrium cephalad to T9. The aorta was seen from T5 to L5.

For the aorta (iliac artery at L5), the measurements obtained in the prone and supine positions are listed in Table 1. These measurements show that the aorta, in the lumbar region, does not move an appreciable amount either anteriorly or posteriorly. The aorta moved a minimal amount at the upper and lower limits in the thoracic region. While at the midthoracic levels, the aorta moved closer to the theoretical anterior cortex exit site for the pedicle screws in the prone position.

For the inferior vena cava (iliac vein at L5), the measurements obtained in the prone and supine positions are listed in Table 2. The inferior vena cava, like the aorta, is relatively immobile in the lumbar region. It does slide anteriorly, away from

Table 2. The distance from the tip of the projected screw to the inferior vena cava.

\begin{tabular}{lrrrrr}
\hline Vertebra & L5 & L3 & L1 & T11 & T9 \\
\hline Prone, mm & 2.4 & 4.3 & 8.4 & 10.2 & 10.4 \\
Supine, mm & 2.3 & 4.4 & 10.1 & 8.4 & 8.8 \\
Change, mm & 0.1 & -0.1 & -1.7 & 1.8 & 1.6 \\
\hline
\end{tabular}

the pedicle screw exit site in the thoracic region. However, it is intrahepatic at these levels and is not at significant risk for injury there.

The average of the measurements at each level were compared in the supine versus prone position. The change in distance was measured between the 2 positions and used as our primary statistical outcome measure.

\section{DISCUSSION}

Improved accuracy of pedicle screw placement can be expected with the development of stereotactic navigational tools. Mason et $\mathrm{al}^{6}$ performed a systematic analysis to review the literature in order to compare the accuracy of pedicle screw placement using conventional fluoroscopy (12 data sets), 2dimensional (2D; 8 data sets), and 3D (20 data sets) navigation systems. The studies reviewed included a total of 1973 patients. The accuracy was found to be $68.1 \%, 84.3 \%$ and $95.5 \%$ for conventional fluoroscopy, 2D, and 3D navigation systems respectively. ${ }^{6}$ Verma et $\mathrm{al}^{7}$ compared screw placement accuracy while using the conventional $\mathrm{C}$-arm fluoroscopy versus the $\mathrm{O}$-arm navigation software. They found the $\mathrm{O}$-arm and conventional $\mathrm{C}$-arm groups to have a statistically significant inaccuracy rate of $0.93 \%$ and $8.79 \%$, respectively. With the benefit of the increased accuracy of this virtual reality tool, increased pedicle screw strength could be obtained by gaining anterior cortical purchase. Zindrick et $\mathrm{al}^{9}$ showed that the pull-out strength for $6.5-\mathrm{mm}$ screws increased by $31 \%$, whereas $\mathrm{Krag}$ et $\mathrm{al}^{8}$ found a $20 \%$ to $25 \%$ improvement. However, these studies do not account for the position of the great vessels in the operative position, which is traditionally prone. The navigation images used as a reference for screw placement are taken commonly when the patient is supine.

In our study, we found that the great vessels in the thoracic region move anteriorly, as expected with prone positioning. However, the aorta rolls along the anterior thoracic vertebral body in the prone position and actually comes closer to the anterior exit site of the screw. Soft tissue tethering of the aortic arch and diaphragm allow for minimal 
movement of the aorta at these regions (T5, T11), maintaining its position anterior to the vertebral body in the location where a screw would exit the anterior cortex. We hypothesize that the diaphragm, soft tissue attachments, and/or anterior segmental vessels may also act to prevent translation in the lumbar region, where we found no significant movement of either vessel.

Several studies have been performed to evaluate the safety of pedicle screw placement in relation to the great vessels in subjects lying supine. Takeshita et $\mathrm{al}^{11}$ supported the tethering of the aorta in supine subjects in the thoracic spine around the aortic arch near T4, T5, and also at the lower thoracic spine near the diaphragm from $\mathrm{T} 10$ to $\mathrm{T} 12$. The aortic arch and diaphragm appear to tether the aorta to the anterior vertebral wall, further supporting the inherent risk of anterior pedicle screw placement in these regions. ${ }^{11-14}$

Individual variability of the patient's condition is important to consider. Takeshita et $\mathrm{al}^{11}$ found that after correction of right thoracic scoliosis, the aorta moved into a more anterior medial position on the vertebral body, similar to the position found in the healthy participant group. ${ }^{11}$ Other deformities, such as kyphosis, could impact the position of the great vessels as well. In patients with thoracolumbar kyphosis from ankylosing spondylitis, Feng et $\mathrm{al}^{15}$ described the aorta tethered close to the anterior vertebral body at T12, L1, and positioned farther away anteriorly in the thoracic and lumbar spine with increasing distance from the thoracolumbar junction. The movement of the aorta away from the thoracic spine and the lumbar spine with a tether point at the thoracolumbar junction is reminiscent of a hammock in this subset of kyphotic patients. If a study were performed with kyphotic patients in the prone position and showed a maintained distance of the aorta from the vertebral body, this anatomic subset of patients could be more protected from anteriorly placed pedicle screws.

The participants evaluated in our study were relatively young and healthy and were not being evaluated as spine surgery candidates, which is a selection bias. If we had another arm of the study with patients who had spinal deformities, such as kyphosis or scoliosis, we would have data that could give insight into the surgical planning for these patients in the prone position. In addition, trauma patients who have suffered disruption of the soft tissues in the retroperitoneum or mediastinum may have shown different results as well. Lastly, other physiologic considerations, such as inspiration, may increase the variability of movement of the aorta, which is a variable we did not take into account.

Because of the proximity of the great vessels to the anterior cortex of the vertebrae in the prone position, placing pedicle screws that engage the anterior cortex may be even higher risk than we had thought. Vaccaro et $\mathrm{al}^{10}$ evaluated the relationship of the great vessels to the vertebrae in the lumbar region in individuals when supine and prone. They found significant movement of the vessels with change in positioning, which supports the need for more accurate intraoperative knowledge of the whereabouts of the vasculature when planning surgery. ${ }^{10}$

Reference imaging for navigation systems is commonly done in the supine position. These static supine reference images do not account for the vessel position when prone. As a result, we do not believe navigation is able to make anterior fixation of pedicle screws safer, unless it were to account for the dynamic positioning of the vasculature.

\section{REFERENCES}

1. Esses SI, Sachs BL, Dreyzin V. Complications associated with the technique of pedicle screw fixation. Spine (Phila Pa 1976). 1993;18(15):2231-2239.

2. Vaccaro AR, Rizzolo SJ, Balderston RA, et al. Placement of pedicle screws in the thoracic spine: part ii: an anatomical and radiographic assessment. JBJS. 1995;77-A(8):1200-1206.

3. Anda S, Aakhus S, Skaanes KO, Sande E, Schrader H. Anterior perforations in lumbar discetomies; a report of four cases of vascular complications and a ct study of the prevertebral lumbar anatomy. Spine (Phila Pa 1976). 1991;16(1):54-60.

4. Hicks JM, Singla A, Shen FH, Arlet V. Complications of pedicle screw fixation in scoliosis surgery: a systematic review. Spine (Phila Pa 1976). 2010;35(11):465-470.

5. Kakkos SK, Shepard AD. Delayed presentation of aortic injury by pedicle screws: report of two cases and review of the literature. J Vasc Surg. 2008;47(5):1074-1082.

6. Mason A, Paulsen R, Babuska JM, et al. The accuracy of pedicle screw placement using intraoperative image guidance systems. J Neurosurg Spine. 2014;20(2):196-203.

7. Verma SK, Singh PK, Agrawal D, et al. O-arm with navigation versus $\mathrm{C}$-arm: a review of screw placement over 3 years at a major trauma center. Br J Neurosurg. 2016;30(6):658661.

8. Krag MH, Beynnon BD, Pope MH, Decoster TA. Depth of insertion of transpedicular screws into human vertebrae: effect upon screw-vertebra interface strength. J Spinal Disord. 1988;1(4):287-294.

9. Zindrick MR, Wiltse LL, Widell EH, et al. A biomechanical study of intrapeduncular screw fixation in the lumbosacral spine. Clin Orthop Relat Res. 1988;203:99-112. 
10. Vaccaro AR, Kepler CK, Jrihn JA, et al. Anatomical relationships of the anterior blood vessels to the lower lumbar intervertebral discs. J Bone Joint Surg Am. 2012;94(12):10881094.

11. Takeshita K, Maruyama T, Nakao Y, et al. Aorta movement in patients with scoliosis after posterior surgery. Spine (Phila Pa 1976). 2010;35(26):1571-1576.

12. Liu J, Shen J, Zhang J, et al. The position of the aorta relative to the spine for pedicle screw placement in the correction of idiopathic scoliosis. J Spinal Disord Tech. 2012;25(4):103-107.

13. Sarlak AY, Buluc L, Sarisoy HT, Memisoglu K, Tosun B. Placement of pedicle screws in thoracic idiopathic scoliosis: a magnetic resonance imaging analysis of screw placement relative to structures at risk. Eur Spine J. 2008;17(5):657-662.

14. Qiao J, Zhu F, Xu L, et al. Comparison of the aorta impingement risks between thoracolumbar/lumbar curves with different convexities in adolescent idiopathic scoliosis: a computed tomography study. Eur Spine J. 2012;21(10):20432049.

15. Feng F, Qian BP, Qiu Y, et al. Position of the aorta relative to the spine in patients with thoracolumbar/lumbar kyphosis secondary to ankylosing spondylitis. Spine (Phila Pa 1976). 2013;38(20):1235-1241.

Disclosures and COI: The authors received no funding for this study and report no conflicts of interest.

Corresponding Author: Alexander R. Riccio, Department of Neurosurgery, Albany Medical Center, 43 New Scotland Ave, Albany, NY 12208. Phone: (518) 810-2736

Published 30 April 2019

This manuscript is generously published free of charge by ISASS, the International Society for the Advancement of Spine Surgery. Copyright (C) 2019 ISASS. To see more or order reprints or permissions, see http://ijssurgery.com. 